\title{
On the Modification of Newton-Secant Method in Solving Nonlinear Equations for Multiple Zeros of Trigonometric Function
}

\author{
Juhari \\ Department of Mathematics, Faculty of Science and Technology, Maulana Malik Ibrahim \\ Islamic State University of Malang
}

Email: juhari@uin-malang.ac.id

\begin{abstract}
This study discusses the construction of mathematical model modification of Newton-Secant method and solving nonlinear equations for multiple zeros by using a modified Newton-Secant method. A nonlinear equations for multiple zeros or multiplicity $m>1$ is an equation that has more than one root. The first step is to construct of mathematical model Newton-Secant method and its modification, namely to construct a mathematical model of the Newton-Secant method using the concept of the Newton method and the concept of the Secant method. The second step is to construct a modified mathematical model of the Newton-Secant method by adding the parameter $\theta$. After obtaining the formula for the modification Newton-Secant method, then applying the method to solve a nonlinear equations for multiple zeros. In this case, it is applied to the nonlinear equation trigonometric function $f(x)=\left(\cos ^{2} x+x\right)^{5}$ which has a multiplicity of $m=5$. The solution is done by selecting four different initial guess, namely $-2 ;-0,8 ;-0,2$ and 2. Furthermore, to determine the effectivity of this method, the researcher compared the result with the Newton-Raphson method, the Secant method, and the Newton-Secant method that has not been modified. The obtained results from the construction of mathematical model NewtonSecant method and its modification is an iteration formula modification of Newton-Secant method. And for the result of $f(x)$ using a modification of Newton-Secant method with four different initial guess, the root of $x$ is obtained approximately, namely -0.641714371 with fewer iterations if compared to using the Newton method, the Secant method, and the Newton-Secant method. Based on the problem to find the root of the nonlinear equation $f(x)$ it can be concluded that the modification of Newton-Secant method is more effective than the Newton method, the Secant method, and the Newton-Secant method.
\end{abstract}

Keywords: modification; Newton-Secant method; nonlinear equation; multiple zeros; trigonometric function

\section{INTRODUCTION}

In the fields of science, engineering and economics often involve problems mathematics. Mathematical problems are often found in the form of nonlinear equations [1]. Nonlinear equations in the form of functions $f(x)$ can be form of algebraic equations and transcendent equations. Transcendent equations or non-algebraic equations are equations that cannot be expressed in algebraic operations. This equation consists of logarithmic functions, exponential functions, hyperbolic functions and trigonometric 
functions [2]. In finding a solution to a nonlinear equation means making that equation becomes zero, i.e. $f(x)=0$ [3]. In determining the solution of a complex nonlinear equation will be difficult if done using analytical methods so the numerical will be solution to this problem [4]. The solution obtained from the numerical method an approximate solution. The approximate solution is different from the exact solution, so there is the difference between exact solution and approximate solution. This difference is often referred to as an error [5].

In finding the roots of a nonlinear equation, it is not always singular or simple, sometimes nonlinear equations are in the form of multiple nonlinear equations, meaning the equation has a multiplicity $m>1$. The following is the definition of multiplicity:

\section{Definition 1 (Multiplicity)}

The root $\alpha$ of $f(x)$ is said to have multiplicity $(m)$ if

$$
f(x)=(x-\alpha)^{m} h(x)
$$

for $h(x)$ a continuous function with $h(x) \neq 0$, and $m$ is a positive integer. If $m=1$ then $\alpha$ is called a simple root. If $m \geq 2$ then $\alpha$ is called a multiple root [6]. Thus it can be said that a function has multiplicity if the multiplicity of a function is more than one [5].

The most famous numerical method for solving nonlinear equations is the Newton-Raphson method. In finding solutions to nonlinear equations, this method requires one initial guess and function derivative value. This method will fail if the initial guess selection gives the derivative value zero [7]. The following is the formula of Newton-Raphson method :

$$
x_{n+1}=x_{n}-\frac{f\left(x_{n}\right)}{f^{\prime}\left(x_{n}\right)}
$$

with $n=0,1,2, \ldots$ and $f^{\prime}\left(x_{n}\right) \neq 0$.

The numerical method that is no less famous is the Secant method. This method able to overcome the weakness of the Newton-Raphson method. In the Newton-Raphson method is required first derivative of the function $f(x)$. The process of finding the derivative function $f(x)$ does not always easy, sometimes there are some functions that are difficult to find the derivative value. To overcome the weakness of Newton's method then in the Secant method derivative function is replaced by another equivalent form. So the secant method does not require another derivative of the function but requires two initial guesses [8]. The following is the formula of Secant method :

with $n=1,2,3 \ldots$

$$
x_{n+1}=x_{n}-\frac{f\left(x_{n}\right) \cdot\left(x_{n-1}-x_{n}\right)}{f\left(x_{n-1}\right)-f\left(x_{n}\right)}
$$

In the calculation process using numerical method such as Newton's method and the Secant method are needed initial guess. Determining the initial value will be easier if you pay attention the theory related the intermediate value theorem. The intermediate value theorem is a theorem that is used to determine the presence or absence of a solution at a certain interval limit.

\section{Theorem 1 (Intermediate Value Theorem)}

If $f \in C[a, b]$ and $K$ is any number between $f(a)$ and $f(b)$, then there exists a number $c$ in $(a, b)$ for which $f(c)=K$. [9]

Another theorem that is almost similar with the intermediate value theorem is Bolzano's theorem. 


\section{Theorem 2 (Bolzano's Theorem)}

If $f:[a, b] \subset \mathbb{R} \rightarrow \mathbb{R}$ is a continuous function and if $f(a) \cdot f(b)<0$, then there is at least one root $x \in(a, b)$ such that $f(x)=0$. [10]

Each numerical method has a different order of conver gence. Order of convergence is the speed of an iteration method in finding the roots simultaneously approximation of the equation of function $f$. The following is the definition of convergence :

\section{Definition 2 (convergence)}

Let the sequence $x_{1}, x_{2}, \ldots, x_{n}$ convergence to $\alpha$ and $e_{n}=x_{n}-\alpha$ where $n \geq 0$. If the order of convergence $p>0$ and error constant $C \neq 0$, with

$$
\lim _{n \rightarrow \infty} \frac{\left|x_{n+1}-\alpha\right|}{\left|x_{n}-\alpha\right|^{p}}=\lim _{n \rightarrow \infty} \frac{\left|e_{n+1}\right|}{\left|e_{n}\right|^{p}}=C
$$

then the sequence $\left\{x_{n}\right\}$ converges to $\alpha$ with the order of convergence $p$ [11].

If $p=1$ then the iteration method has a linear convergence order. If $p=2$ then the iteration method has a quadratic order of convergence. If $1<p<2$ then iteration method has a superlinear order of convergence [12]. If $p=3$ then the iteration method has a cubic order of convergence [13]. Numerical methods such as the Newton-Raphson method have the quadratic order of convergence. While the Secant method has a superlinear order of convergence [12].

Numerical methods often experience developments. The development aims to find methods that are considered more effective in solving existing problems [14]. Based on this in 2002 Kasturiarachi combine Newton's method and the Secant method become a new method, namely the leap-frogging Newton's method or Newton-Secant method [13]. This method has a cubic convergence when used to solve simple nonlinear equations. Whereas if used to solve multiple zeros of nonlinear equations the convergence to be linear. Therefore, in [15] modified Newton-Secant method with the addition of parameter $\theta$. The purpose of this modification, namely to maintain the order of convergence Newton-Secant method to remain cubic, if used to find the roots of nonlinear equations [15]. The following theorem related to the parameter $\theta$ used to modify the Newton-Secant method:

\section{Theorem 3}

Let $\alpha \in D$ be multiple root of a sufficiently differentiable function $f: D \subset \boldsymbol{R} \rightarrow \boldsymbol{R}$ on an open interval $D$ with multiplicity $m>1$, which includes $x_{0}$ as an initial approximation of $\alpha$. Then, the modification of Newton-Secant method has order three and $\theta=$ $\left(\frac{-1+m}{m}\right)^{-1+m}, m \in Z^{+}$.

\section{Proof:}

Let $\alpha$ is multiple zero of equation $f(x)=0$, then $f(\alpha)=0$ and $f^{\prime}(\alpha) \neq 0$. Next, suppose

$$
\begin{gathered}
e_{n}:=x_{n}-\alpha \\
e_{n, \bar{x}}:=\overline{x_{n}}-\alpha \\
c_{i}:=\frac{m !}{(m+i) !} \frac{f^{(m+i)}(\alpha)}{f^{(m)}(\alpha)}
\end{gathered}
$$

Using the Taylor expansion of $f\left(x_{n}\right)$ around $x_{n}=\alpha$ we get

simplified to

$$
f\left(x_{n}\right)=c_{0} e_{n}^{m}+c_{1} e_{n} e_{n}^{m}+c_{2} e_{n}^{2} e_{n}^{m}+c_{3} e_{n}^{3} e_{n}^{m}+O\left(e_{n}^{4}\right)
$$

and

$$
f\left(x_{n}\right)=e_{n}^{m}\left(c_{0}+c_{1} e_{n}+c_{2} e_{n}^{2}+c_{3} e_{n}^{3}\right)+O\left(e_{n}^{4}\right),
$$




$$
f^{\prime}\left(x_{n}\right)=e_{n}^{m-1}\left(m+(m+1) c_{1} e_{n}+(m+2) c_{2} e_{n}^{2}+(m+3) c_{3} e_{n}^{3}+O\left(e_{n}^{4}\right)\right) .
$$

If equation (3) is divided by equation (4), then we get

$$
\frac{f\left(x_{n}\right)}{f^{\prime}\left(x_{n}\right)}=e_{n}\left(\frac{\left(c_{0}+c_{1} e_{n}+c_{2} e_{n}^{2}+c_{3} e_{n}^{3}\right)+O\left(e_{n}^{4}\right)}{\left(m+(m+1) c_{1} e_{n}+(m+2) c_{2} e_{n}^{2}+(m+3) c_{3} e_{n}^{3}+O\left(e_{n}^{4}\right)\right)}\right)
$$

Furthermore, equation (5) can be written as

and since

$$
\frac{f\left(x_{n}\right)}{f^{\prime}\left(x_{n}\right)}=\frac{1}{m} e_{n}-\frac{c_{1}}{m^{2} c_{0}} e_{n}^{2}+\frac{-(1+m) c_{1}^{2}+2 m c_{0} c_{2}}{m^{3} c_{0}^{2}} e_{n}^{3}+O\left(e_{n}^{4}\right),
$$

$$
\begin{aligned}
e_{n, \bar{x}} & =\overline{x_{n}}-\alpha \\
& =\frac{-1+m}{m} e_{n}-\frac{c_{1}}{m^{2} c_{0}} e_{n}^{2}+\frac{-(1+m) c_{1}^{2}+2 m c_{0} c_{2}}{m^{3} c_{0}^{2}} e_{n}^{3}+O\left(e_{n}^{4}\right) .
\end{aligned}
$$

For $f\left(\overline{x_{n}}\right)$ we have

$$
f\left(\overline{x_{n}}\right)=e_{n, \bar{x}}^{m}\left(c_{0}+c_{1} e_{n, \bar{x}}+c_{2} e_{n, \bar{x}}^{2}+c_{3} e_{n, \bar{x}}^{3}\right)+O\left(e_{n, \bar{x}}^{4}\right)
$$

Substituting (3)-(8) in modification of Newton-Secant method formula, which the method will be constructed in the Research Results section. So we get

where

$$
e_{n+1}=D_{1} e_{n}+D_{2} e_{n}^{2}+D_{3} e_{n}^{3}+O\left(e_{n}^{4}\right)
$$

and

$$
D_{1}=1+\frac{\theta}{m\left(-\theta+\left(\frac{-1+m}{m}\right)^{m}\right)},
$$

and

$$
D_{2}=\frac{\theta m^{-2+m}\left(-m(-1+m)^{m}+\theta m^{m}(-1+m)\right) c_{1}}{(-1+m)\left((-1+m)^{m}-\theta m^{m}\right)^{2} c_{0}} \text {, }
$$

where

$$
D_{3}=\frac{\theta m^{-3+m} A}{2(-1+m)^{2}\left((-1+m)^{m}-\theta m^{m}\right)^{3} c_{0}^{2}},
$$

$$
\begin{aligned}
A=(-1+m)^{2 m}\left(-1+m+2 m^{2}\right)\left(m c_{1}^{2}-2(-1+m) c_{0} c_{2}\right) \\
+2 \theta^{2}(-1+m)^{2} m^{2 m}\left((1+m) c_{1}^{2}-2 m c_{0} c_{2}\right) \\
-\theta(-1+m)^{1+m}\left(m(3+4 m) c_{1}^{2}+2\left(1+m-4 m^{2}\right) c_{0} c_{2}\right) .
\end{aligned}
$$

Therefore, to provide the three order of convergence, it is need to choose $D_{i}=$ $0(i=1,2)$, so we have

and the error equation becomes

$$
\theta=\left(\frac{-1+m}{m}\right)^{-1+m},
$$

$$
e_{n+1}=\left(\frac{m c_{1}^{2}-2(-1+m) c_{0} c_{2}}{2 m^{2} c_{0}^{2}}\right) e_{n}^{3}+O\left(e_{n}^{4}\right),
$$

and modification of Newton-Secant method has convergence order of three [15].

Based on the description above the researcher intends to construct the modification of Newton-Secant method in solving nonlinear equations for multiple zeros. Then apply the method to solve the nonlinear equations for multiple zeros. In this case, it is applied to a nonlinear trigonometric function. To determine the effectivity of modification of Newton-Secant method then the solution will also be compared with Newton method, Secant method, and Newton-Secant method. 


\section{METHODS}

\section{Research Steps}

1. Construction of mathematical model Newton-Secant method and its modification with the following steps:

a) Construction of mathematical model Newton-Secant method.

- Analyzing the theory related to the origin of the Newton-Secant method based on Kasturiarachi's article 2002 entitled LeapFrogging Newton's Method.

- Performing analysis to obtain Newton's approximation by using the equation of the tangent $\left(x_{0}, f\left(x_{0}\right)\right)$ that intersects $\left(\overline{x_{0}}, 0\right)$.

- Create an equation of a secant connecting the points $\left(x_{0}, f\left(x_{0}\right)\right)$ and $\left(\overline{x_{0}}, f\left(\overline{x_{0}}\right)\right)$ using the equation of the line that passes through two point and assumes a secant that satisfies the $x$-axis on point $\left(x_{1}, 0\right)$.

- Substituting Newton's approximation into the equation of secant connecting the points $\left(x_{0}, f\left(x_{0}\right)\right)$ and $\left(\overline{x_{0}}, f\left(\overline{x_{0}}\right)\right)$.

- Write the iteration formula based on the process that has been done at the stages above.

b) Construction of mathematical model modification of Newton-Secant method with adding parameter $\theta$ to the second term of the Newton-Secant method. In this case, theorem 3 is used which is in the Introduction section.

2. Solving nonlinear equation that have a multiplicity $m>1$ using modification of Newton-Secant method. In this case the solution is done by selecting two different initial values. After that the researcher compared the result with the Newton-Raphson method, Secant method, and Newton-Secant method that has not been modified. This comparison aims to determine the effectivity of modification of Newton-Secant method if when viewed from the iterations, convergence, and time needed to solve a nonlinear equation having a multiplicity of $m>1$.

\section{RESULTS AND DISCUSSION}

\section{Construction of mathematical model Newton-Secant method and its modification}

\section{a. Construction of mathematical model Newton-Secant method}

Newton-Secant method or also known as leap-frogging Newton's method is a combination of Newton method and Secant method. Based on this to do construction of mathematical model Newton-Secant method used the concept of Newton's method and the concept of the secant method. Suppose that the function $f(x)$ has the zero $\alpha$ in the interval $[a, b]$ and $f \in C^{2}[a, b]$. Let $x_{0}$ be the initial guess. If the equation of the tangent line at $\left(x_{0}, f\left(x_{0}\right)\right)$ intersects $\left(\overline{x_{0}}, 0\right)$ then by using the concept of Newton's method geometrically as follows : 


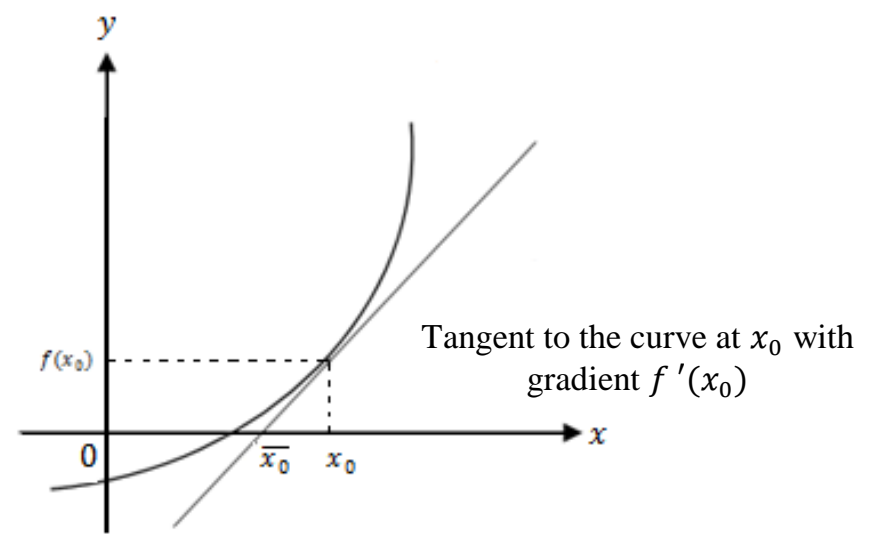

Figure 1. Newton's Approximation Curve

Then we get Newton's approximation :

$$
\begin{aligned}
f^{\prime}\left(x_{n}\right) & =\frac{\Delta y}{\Delta x} \\
f^{\prime}\left(x_{0}\right) & =\frac{f\left(x_{0}\right)-0}{x_{0}-\overline{x_{0}}} \\
f^{\prime}\left(x_{0}\right)\left(x_{0}-\overline{x_{0}}\right) & =f\left(x_{0}\right) \\
x_{0}-\overline{x_{0}} & =\frac{f\left(x_{0}\right)}{f^{\prime}\left(x_{0}\right)} \\
\overline{x_{0}} & =x_{0}-\frac{f\left(x_{0}\right)}{f^{\prime}\left(x_{0}\right)}
\end{aligned}
$$

In this case used $\overline{x_{0}}$ instead of $x_{1}$ because this is only used as an intermediate approximation.

Furthermore find the equation of the secant line connecting the points $\left(x_{0}, f\left(x_{0}\right)\right)$ and $\left(\overline{x_{0}}, f\left(\overline{x_{0}}\right)\right)$. To find these equations is used the concept of the Secant method geometrically. Look at the following curve :

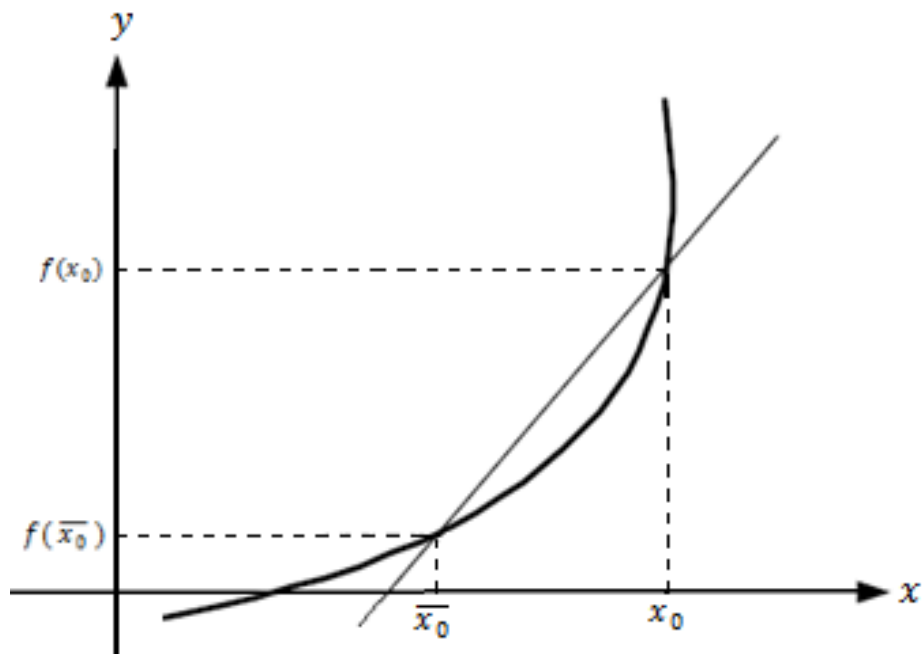

Figure 2. The Concept of Secant Method to Find the Equation of the Secant line

Based on Figure 2 above, the following gradient is obtained:

$$
\begin{aligned}
f^{\prime}\left(x_{0}\right) & =\frac{\Delta y}{\Delta x} \\
& =\frac{\left[f\left(x_{0}\right)-f\left(\overline{x_{0}}\right)\right]}{x_{0}-\overline{x_{0}}}
\end{aligned}
$$


The gradient is used to get the equation of the line connecting the points $\left(x_{0}, f\left(x_{0}\right)\right)$ and $\left(\overline{x_{0}}, f\left(\overline{x_{0}}\right)\right)$. Based on the gradient formula to find the equation of the line that through two points, the following equation is obtained :

$$
y-f\left(x_{0}\right)=\frac{f\left(x_{0}\right)-f\left(\overline{x_{0}}\right)}{x_{0}-\overline{x_{0}}}\left(x-x_{0}\right)
$$

Assume the secant line meets the $\mathrm{x}$-axis at the point $\left(x_{1}, 0\right)$. So with substituting a value of $x_{1}$ in $x$ and value of 0 in $y$ in equation (10) then we get,

$$
\begin{aligned}
& 0-f\left(x_{0}\right)=\frac{\left[f\left(x_{0}\right)-f\left(\overline{x_{0}}\right)\right]}{x_{0}-\overline{x_{0}}}\left(x_{1}-x_{0}\right) \\
& \frac{0-f\left(x_{0}\right)}{x_{1}-x_{0}}=\frac{\left[f\left(x_{0}\right)-f\left(\overline{x_{0}}\right)\right]}{x_{0}-\overline{x_{0}}} \\
& \frac{-f\left(x_{0}\right)}{x_{1}-x_{0}}=\frac{\left[f\left(x_{0}\right)-f\left(\overline{x_{0}}\right)\right]}{\left(x_{0}-\overline{x_{0}}\right)} \\
& {\left[f\left(x_{0}\right)-f\left(\overline{x_{0}}\right)\right] \cdot\left(x_{1}-x_{0}\right)=-f\left(x_{0}\right) \cdot\left(x_{0}-\overline{x_{0}}\right)} \\
& x_{1}-x_{0}=\frac{-f\left(x_{0}\right) \cdot\left(x_{0}-\overline{x_{0}}\right)}{\left[f\left(x_{0}\right)-f\left(\overline{x_{0}}\right)\right]} \\
& x_{1}=x_{0}-\frac{f\left(x_{0}\right) \cdot\left(x_{0}-\overline{x_{0}}\right)}{\left[f\left(x_{0}\right)-f\left(\overline{x_{0}}\right)\right]}
\end{aligned}
$$

Then substitute Newton's approximation (9) into equation (11) so that optained,

$$
\begin{aligned}
x_{1} & =x_{0}-\frac{f\left(x_{0}\right) \cdot\left(x_{0}-\left(x_{0}-\frac{f\left(x_{0}\right)}{f^{\prime}\left(x_{0}\right)}\right)\right)}{\left[f\left(x_{0}\right)-f\left(\overline{x_{0}}\right)\right]} \\
& =x_{0}-\frac{f\left(x_{0}\right) \cdot\left(\frac{f\left(x_{0}\right)}{f^{\prime}\left(x_{0}\right)}\right)}{\left[f\left(x_{0}\right)-f\left(\overline{x_{0}}\right)\right]} \\
& =x_{0}-\frac{\frac{\left[f\left(x_{0}\right)\right]^{2}}{f^{\prime}\left(x_{0}\right)}}{\left[f\left(x_{0}\right)-f\left(\overline{x_{0}}\right)\right]} \\
& =x_{0}-\frac{\left[f\left(x_{0}\right)\right]^{2}}{f^{\prime}\left(x_{0}\right)\left[f\left(x_{0}\right)-f\left(\overline{x_{0}}\right)\right]}
\end{aligned}
$$

Repeating this above process, the iteration formula can be written as following :

where

$$
x_{n+1}=x_{n}-\frac{\left[f\left(x_{n}\right)\right]^{2}}{f^{\prime}\left(x_{n}\right)\left[f\left(x_{n}\right)-f\left(\overline{x_{n}}\right)\right]}, \quad n=0,1,2, \ldots
$$

$$
\overline{x_{n}}=x_{n}-\frac{f\left(x_{n}\right)}{f^{\prime}\left(x_{n}\right)}
$$

Thus, we get equation (13) is the iteration formula for the Newton-secant method.

\section{b. Construction of mathematical model modification of Newton-Secant method}

In solving simple nonlinear equations the Newton-Secant method has cubic convergence. While to solve the nonlinear equations for multiple zeros or multiplicity $m>1$ the convergence is not cubic but becomes linear. Therefore, to maintain the convergence of the Newton-Secant method to remain cubic it is necessary to modify the method. The process modification of Newton-Secant method is done by adding parameter $\theta$ to the second term of the Newton-Secant method formula. The addition of these parameter resulted in the convergence of the modification of Newton-Secant method is cubic. 

form,

The formula for the Newton-Secant method (13) can be written in the following

$$
x_{n+1}=x_{n}-\frac{f\left(x_{n}\right)}{f\left(x_{n}\right)-f\left(\overline{x_{n}}\right)} \cdot \frac{f\left(x_{n}\right)}{f^{\prime}\left(x_{n}\right)}, \quad n=0,1,2, \ldots
$$

Refer to theorem 3 in the Introduction section to the construction of mathematical model modification of Newton-Secant method is done by adding parameter $\theta$ to the second term Newton-Secant method. So that the iteration formula is obtained as following :

where

$$
x_{n+1}=x_{n}-\frac{\theta f\left(x_{n}\right)}{\theta f\left(x_{n}\right)-f\left(\overline{x_{n}}\right)} \cdot \frac{f\left(x_{n}\right)}{f^{\prime}\left(x_{n}\right)}, \quad n=0,1,2, \ldots
$$

$$
\overline{x_{n}}=x_{n}-\frac{f\left(x_{n}\right)}{f^{\prime}\left(x_{n}\right)} \quad \text { and } \quad \theta=\left(\frac{-1+m}{m}\right)^{-1+m}
$$

Thus, we get equation (14) is modification of Newton-Secant method formula which can be used to find solution to nonlinear equations for multiple zeros.

\section{Solving Nonlinear Equation for Multiple Zeros (Trigonometric Function) Use Modification of Newton-Secant Method}

In the previous explanation, the construction of mathematical model NewtonSecant method and its modification has been explained. To know effectivity of modification of Newton-Secant method then it is necessary to apply a modified NewtonSecant method to nonlinear equations for multiple zeros. In this case, it is taken an example of nonlinear equation of trigonometric function, namely

$$
f(x)=\left(\cos ^{2} x+x\right)^{5}
$$

Solving equation $f(x)$ use modification of Newton-Secant method will be applied with four different initial guess, namely $x=-2 ; x=-0,8 ; x=-0,2$ and $x=2$.

The following are the steps to find a solution to the equation $f(x)=\left(\cos ^{2} x+x\right)^{5}$ using modification of Newton-Secant method:

1) Determine the initial guess to be used

The initial guess selection is based on theorem 1 (intermediate value theorem) in the Introduction section. So that the initial guess are chosen, namely $x=-2 ; x=$ $-0,8 ; x=-0,2$ and $x=2$.

2) Finding the derivative of $f(x)$

$f(x)=\left(\cos ^{2} x+x\right)^{5}$

$f^{\prime}(x)=5\left(\cos ^{2} x+x\right)^{4}(-2 \cos x \sin x+1)$.

3) Determine the multiplicity of $f(x)$

Based on the definition of multiplicity in the Introduction section, it can be said that the multiplicity of $f(x)$ is $m=5$.

4) Set the error to be used

In this case the author sets the error used, namely $10^{-10}$.

5) Calculating the value of $\theta$ 


$$
\begin{aligned}
\theta & =\left(\frac{-1+m}{m}\right)^{-1+m} \\
& =\left(\frac{-1+5}{5}\right)^{-1+5} \\
& =\left(\frac{4}{5}\right)^{4} \\
& =0,4096
\end{aligned}
$$

6) Perform iteration using the modification of Newton-Secant method formula.

7) Comparing the modification of Newton-Secant method with the Newton's method, the Secant method, and the Newton-Secant method. It aims to know the effectiveness of the modification of Newton-Secant method in solving nonlinear equations for multiple zeros of trigonometric function.

The following is the result of solving $f(x)=\left(\cos ^{2} x+x\right)^{5}$ using modification of Newton-Secant method, Newton method, Secant method, and Newton-Secant method which has not been modified.

Table 1. Solution $f(x)=\left(\cos ^{2} x+x\right)^{5}$ Use Modification of Newton-Secant Method, Newton Method, Secant Method, and Newton-Secant Method.

\begin{tabular}{clllccc}
\hline $\boldsymbol{f}_{\boldsymbol{i}}$ & $\boldsymbol{x}_{\mathbf{0}}$ & Method & $\mathbf{n}$ & $\boldsymbol{x}_{\boldsymbol{n}}$ & $\boldsymbol{f}\left(\boldsymbol{x}_{\boldsymbol{n}}\right)$ & $\boldsymbol{\varepsilon}$ \\
\hline & & MMNS & 5 & $-0,641714371$ & $1,76869 \mathrm{E}-74$ & 0,0000000000 \\
& -2 & MNS & 61 & $-0,641714371$ & $8,67022 \mathrm{E}-49$ & 0,0000000000 \\
& & MN & 93 & $-0,641714371$ & $1,20449 \mathrm{E}-47$ & 0,0000000000 \\
& & MS & 133 & $-0,641714371$ & $-8,69088 \mathrm{E}-47$ & 0,0000000000 \\
& & MMNS & 4 & $-0,641714371$ & $-4,17656 \mathrm{E}-74$ & 0,0000000000 \\
& $-0,8$ & MNS & 60 & $-0,641714371$ & $-1,81522 \mathrm{E}-48$ & 0,0000000000 \\
& & MN & 92 & $-0,641714371$ & $-2,51216 \mathrm{E}-47$ & 0,0000000000 \\
& & MS & 131 & $-0,641714371$ & $-9,67797 \mathrm{E}-47$ & 0,0000000000 \\
& & MMNS & 4 & $-0,641714371$ & $-9,9601 \mathrm{E}-76$ & 0,0000000000 \\
& & MNS & 62 & $-0,641714371$ & $3,45672 \mathrm{E}-48$ & 0,0000000000 \\
& $-0,2$ & MN & 96 & $-0,641714371$ & $1,88037 \mathrm{E}-47$ & 0,0000000000 \\
& & MS & 132 & $-0,641714371$ & $-7,87677 \mathrm{E}-47$ & 0,0000000000 \\
& & MMNS & 5 & $-0,641714371$ & $9,07176 \mathrm{E}-75$ & 0,0000000000 \\
& & MNS & 64 & $-0,641714371$ & $-9,82514 \mathrm{E}-49$ & 0,0000000000 \\
& & MN & 101 & $-0,641714371$ & $1,84781 \mathrm{E}-47$ & 0,0000000000 \\
& & MS & 133 & $-0,641714371$ & $-8,69088 \mathrm{E}-47$ & 0,0000000000 \\
\hline
\end{tabular}

Information:

$f_{i} \quad$ : Nonlinear equation function with $i=$ $1,2,3, \ldots$

$x_{0} \quad: \quad$ Initial guess or initial value

$\mathrm{n} \quad$ : Many iterations 


$\begin{array}{cll}x_{n} & : & \text { Root of function } \\ f\left(x_{n}\right) & : & \text { Function of root } x_{n} \\ \varepsilon & : & \text { Error }\left(x_{n+1}-x_{n}\right) \\ \text { MMNS } & : & \text { Modification of Newton-Secant method } \\ \text { MNS } & : & \text { Newton-Secant method } \\ \text { MN } & : & \text { Newton method } \\ \text { MS } & : & \text { Secant method }\end{array}$

Based on table 1 above, the error is 0.0000000000 , meaning that the error in the iteration value is less than the error tolerance constant used, namely $\varepsilon<10^{-10}$. Therefore, the iteration process stops and the approximate root is -0.641714371 which is the solution of $f(x)$. In the table above, it can be seen that taking four different initial values, namely $x=-2 ; x=-0,8 ; x=-0,2$ and $x=2$, if the search for a solution uses modification of Newton-Secant method, iterations are needed more little when compared to Newton's method, the secant method, and the Newton-Secant method. Based on the many iterations, it can be said that the modification of Newton-Secant method is more effective in solving the nonlinear equation $f(x)$ when compared to the Newton method, the Secant method, and the Newton-Secant method which have not been modified.

The convergence of error values from the table of calculation results above can be seen in Table 2 and Table 3 below.

Table 2. Convergence Graph Table of Error Values in the Solution of $f(x)$ Using Modification of NewtonSecant Method and Newton-Secant Method

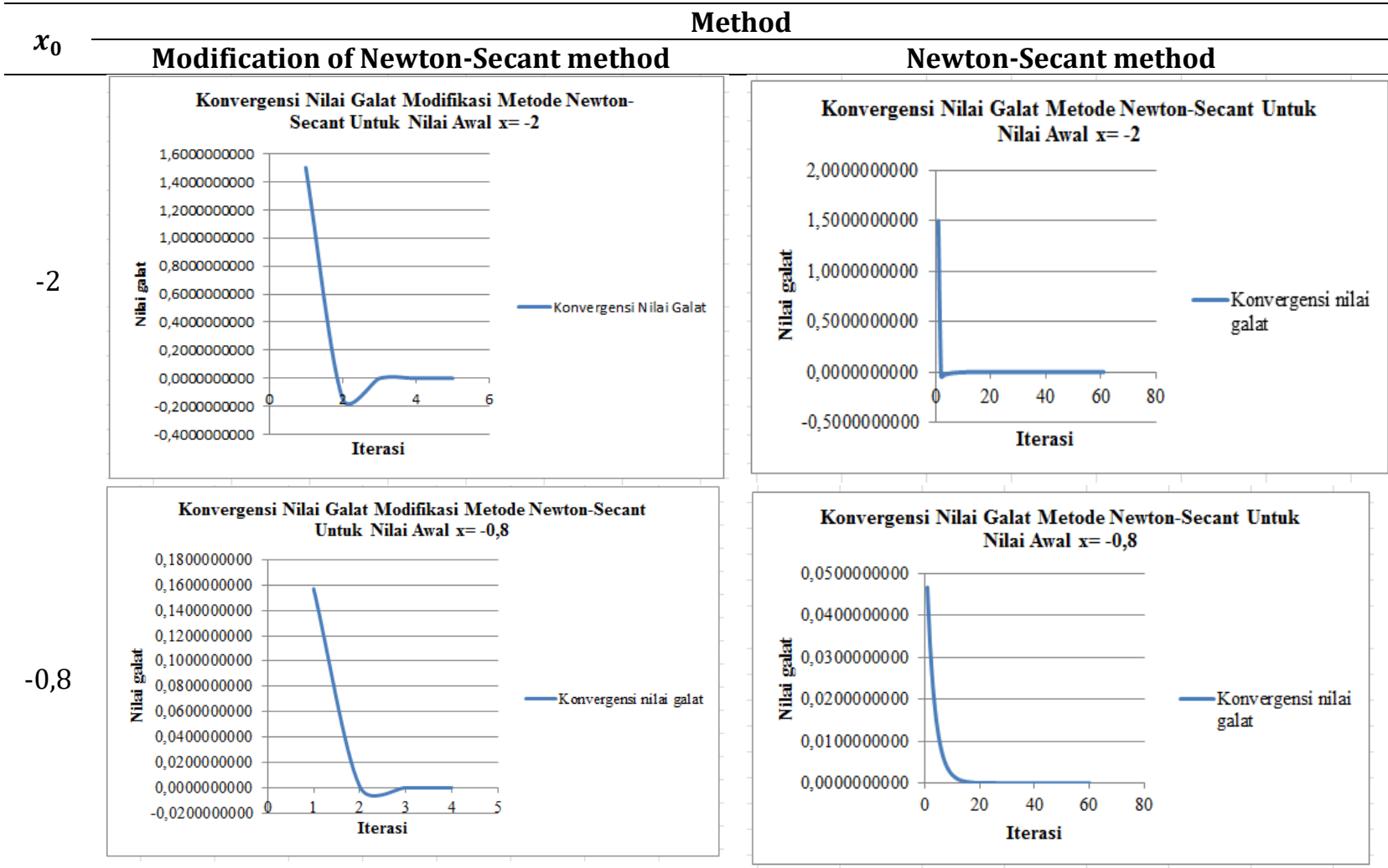



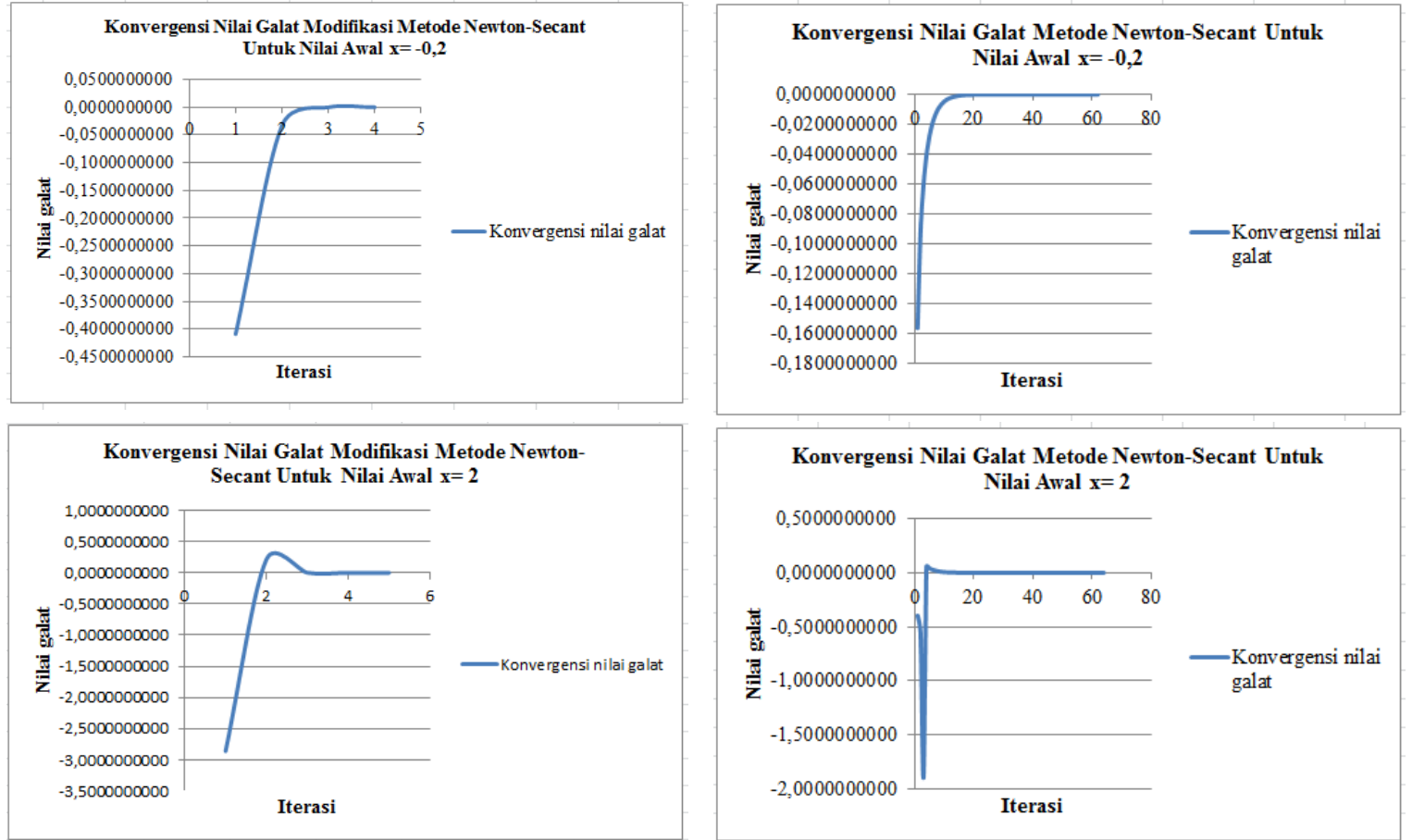

Table 3. Convergence Graph Table of Error Values in the Solution of $f(x)$ Using Newton Method and Secant Method.

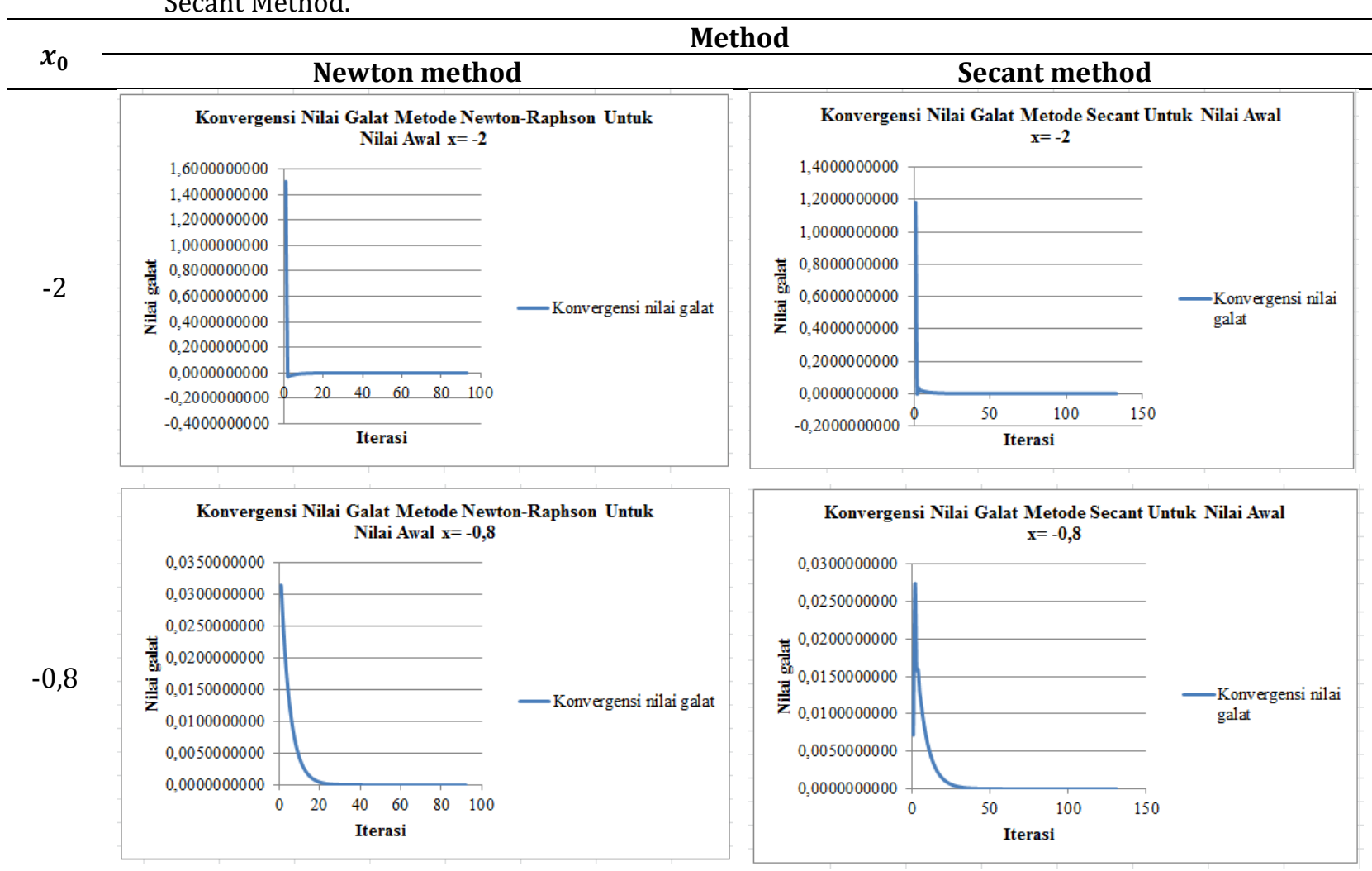




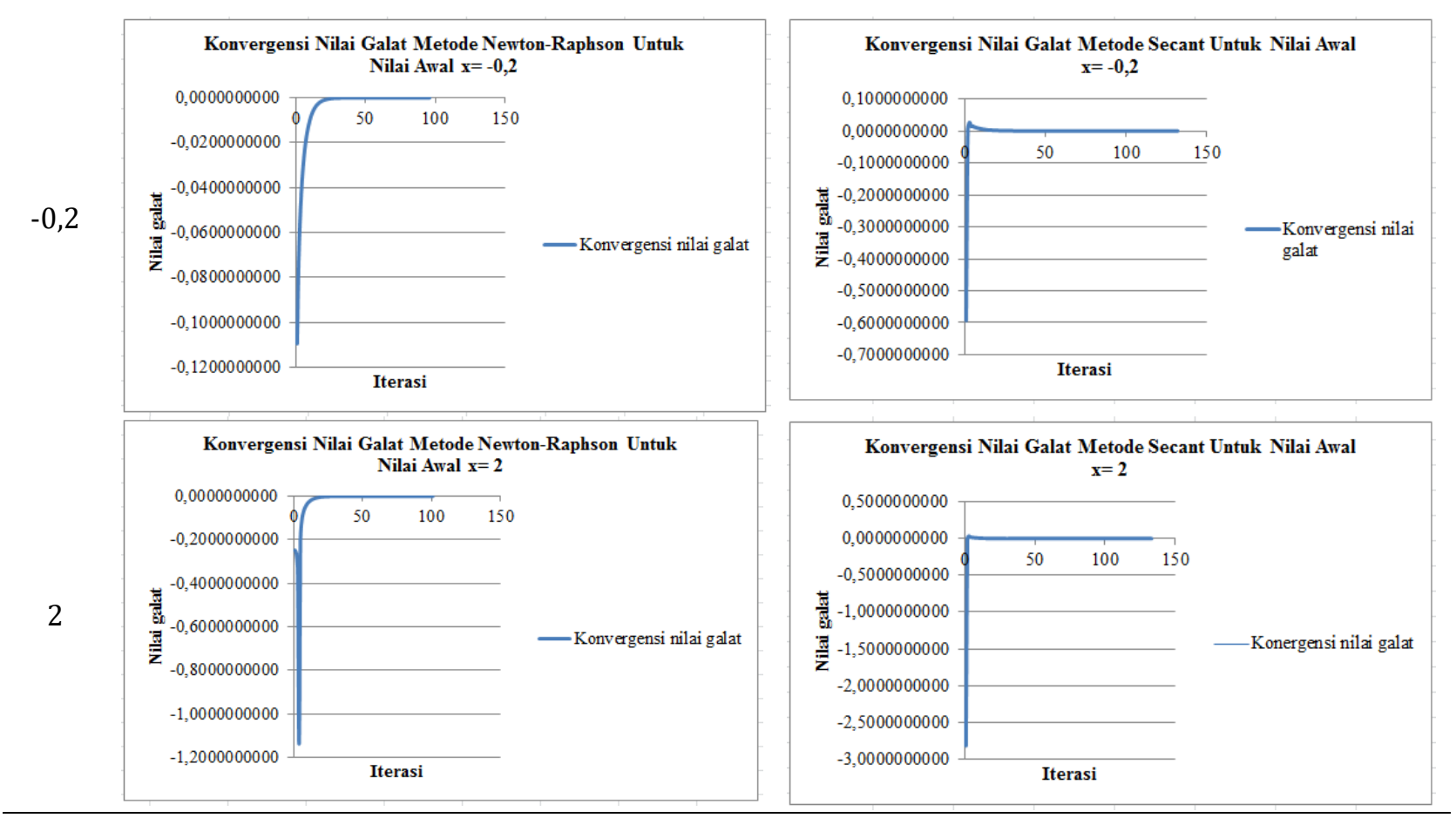

\section{CONCLUSION}

Combining two concepts of numerical method, namely the concept of Newton's method and the concept of Secant method result Newton-Secant method. Then NewtonSecant method modified by adding parameter $\theta$. So we get a new method, namely modification of Newton-Secant method with the following iteration formula:

where

$$
x_{n+1}=x_{n}-\frac{\theta f\left(x_{n}\right)}{\theta f\left(x_{n}\right)-f\left(\overline{x_{n}}\right)} \cdot \frac{f\left(x_{n}\right)}{f^{\prime}\left(x_{n}\right)}, \quad n=0,1,2, \ldots
$$

$$
\overline{x_{n}}=x_{n}-\frac{f\left(x_{n}\right)}{f^{\prime}\left(x_{n}\right)} \quad \text { and } \quad \theta=\left(\frac{-1+m}{m}\right)^{-1+m}
$$

Solution of $f(x)=\left(\cos ^{2} x+5\right)^{5}$ use modification of Newton-Secant method with four different initial guess, namely $x=-2 ; x=-0,8 ; x=-0,2$ and $x=2$ is obtained the root of $x$ approximately, namely $-0,641714371$ with fewer iterations when compared to using the Newton method, the Secant method, and the Newton-Secant method. Based on the problem of finding the root of the nonlinear equation trigonometric function $f(x)$ it can be concluded that the modification of Newton-Secant method is more effective than the Newton method, the Secant method, and the NewtonSecant method that has not been modified.

\section{REFERENCES}

[1] P. Batarius, "Perbandingan Metode Newton-Raphson Modifikasi dan Metode Secant Modifikasi dalam Penentuan Akar Persamaan," 2018.

[2] J. Sapari and S. Bahri, "Penentuan Akar-akar Persamaan Nonlinier dengan Metode Iterasi Baru," Jurnal Matematika UNAND, vol. 4 No. 4, 2015.

[3] P. Batarius, "Nilai Awal pada Metode Newton-Raphson yang Dimodifikasi dalam 
Penentuan Akar Persamaan," Pi: Mathematics Education Journal , vol. 1. No.3, 2018.

[4] Y. Muda, Wartono and N. Maulana, "Konvergensi Modifikasi Metode Newton Ganda dengan Menggunakan Kelengkungan Kurva," Jurnal Sains, Teknologi dan Industri, vol. 9. No. 2, 2012.

[5] R. Munir, Metode Numerik, Bandung: Informatika, 2008.

[6] Z. Lega, Agusni and S. Putra, "Metode Iterasi Tiga Langkah dengan Orde Konvergensi Lima untuk Menyelesaikan Persamaan Nonlinear Berakar Ganda," JOM FMIPA, vol. 1, 2014.

[7] Rochmad, "Aplikasi Metode Newton-Raphson untuk Menghampiri Solusi Persamaan Non Linear," Jurnal MIPA 36(2):193-200(2013), 2013.

[8] S. C. Chapra and R. P. Canale, Numerical Methods for Engineers Sixth Edition, New York: McGraw-Hill Companies, Inc, 2010.

[9] R. L. Burden and J. Faires, Numerical Analysis Ninth Edition, USA: Brooks/Cole Cengage Learning, 2011.

[10] M. N. Vrahatis, "Generalization of the Bolzano Theorem for Simplices," ELSEVIER, 2015.

[11] J. H. Mathews, Numerical Methods for Mathematics, Science, and Engineering, New Jersey: Prentice-Hall Inc, 1992.

[12] R. Kumar and Vipan, "Comparative Analysis of Convergence of Various Numerical Methods," Journal of Computer and Mathematical Sciences, Vols. 6(6),290-297, 2015.

[13] A. B. Kasturiarachi, "Leap-frogging Newton's Method," International Journal of Mathematical Education in Science and Technology, Vols. 33, no. 4, 521-527, 2002.

[14] S. Putra, D. AR and M. Imran, "Kombinasi Metode Newton dengan Metode Secant untuk Menyelesaikan Persamaan Nonlinear," Jurnal EKSAKTA, vol. 2, 2011.

[15] M. Ferrara, S. Sharifi and M. Salimi, "Computing Multiple Zeros by Using a Parameter in Newton-Secant Method," SeMa Journal, 2016. 